\title{
Comunicação
}

[Communication]

\section{Soroprevalência de Maedi-Visna em ovinos na região de Araçatuba, SP}

\author{
(Occurrence of Maedi-visna in sheep from Araçatuba region - SP - Brazil)
}

\author{
A.L. Lombardi ${ }^{1}$, A.H.C. Nogueira ${ }^{1}$, F.C. Feres ${ }^{1}$, H.P. Paulo ${ }^{2}$, R.S. Castro ${ }^{3}$, F.L.F. Feitosa ${ }^{4}$, \\ F.A. Cadioli ${ }^{4}$, J.R. Peiró ${ }^{4}$, S.H.V. Perri ${ }^{4}$, V.F.M. Lima ${ }^{4}$, L.C.N. Mendes ${ }^{4 *}$ \\ ${ }^{1}$ Aluno de pós-graduação - Ciência Animal - UNESP - Araçatuba, SP \\ ${ }^{2}$ Aluna de graduação - Curso de Medicina Veterinária - UNESP - Araçatuba, SP \\ ${ }^{3}$ Universidade Federal de Pernambuco - Recife, PE \\ ${ }^{4}$ Curso de Medicina Veterinária - FO-UNESP - Araçatuba, SP
}

\begin{abstract}
Maedi-Visna (MV) é uma enfermidade multissistêmica de caráter crônico, que não tem tratamento ou vacina para seu controle. Sua ocorrência está relacionada ao sistema de produção, podendo causar perdas econômicas significantes, além de ser limitadora do comércio internacional (Ishizuka et al., 2005). MaediVisna virus (MVV) é classificado na subfamília Orthoretrovirinae, família Retroviridae, gênero Lentivirus (Torsteinsdottir et al., 2007). Os vírus MV e da artrite encefalite caprina (CAE) são denominados de lentivírus de pequenos ruminantes (LVPR) por compartilharem similaridades genéticas (Callado et al., 2001).
\end{abstract}

A imunodifusão em gel de ágar (IDGA) é amplamente utilizada como o método clássico para a detecção de anticorpos contra MVV (Callado et al., 2001; Christodoulopoulos, 2006). A IDGA é específica, reprodutível e prática, mas exige experiência para realizar a leitura (Ishizuka et al., 2005).

Dentre os objetivos do Programa Nacional de Sanidade dos Caprinos e Ovinos estão o controle e a erradicação de Maedi-Visna, incluindo a necessidade de sorologia negativa para obtenção de guia de trânsito animal (GTA) e sacrifício dos animais positivos (Instrução..., 2004).

Os objetivos desse trabalho foram determinar a ocorrência de ovinos soropositivos para Maedi-

Recebido em 6 de novembro de 2008

Aceito em 30 de setembro de 2009

*Autor para correspondência (corresponding author)

E-mail:1mendes@fmva.unesp.br
Visna na região de Araçatuba-SP e diagnosticar a presença de animais sintomáticos, relacionando os resultados com sistema de produção, raça e sexo dos animais testados.

Foram coletadas amostras de sangue de 444 ovinos, sendo 371 fêmeas e 73 machos, com idades entre dois a 12 anos, das raças Dorper $(n=6)$, Highlander $(n=6)$, Primera $(n=1)$, Santa Inês $(n=188)$, Suffolk $(n=87)$ e Texel $(n=2)$ e animais sem raça definida $(n=154)$. Os animais pertenciam a 20 propriedades, escolhidas aleatoriamente; em 11 dessas propriedades, o sistema de criação era extensivo; em seis, intensivo e em três, semiextensivo. Todos os animais foram submetidos ao exame físico geral, que incluiu frequências respiratória e cardíaca, e temperatura retal. $\mathrm{O}$ sangue foi coletado por punção da veia jugular, utilizando-se agulhas acopladas a tubos à vácuo ${ }^{1}$. Após a retração do coágulo, em temperatura ambiente, o sangue foi centrifugado a 1303 x g por cinco minutos, o soro obtido foi transferido para tubo de polipropileno e mantido a $-20^{\circ} \mathrm{C}$ até seu processamento. Os exames foram realizados utilizando-se o kit para diagnóstico de MaediVisna (IDGA) ${ }^{2}$. A leitura das lâminas foi feita após 48 horas de incubação, por no mínimo três observadores. Os animais que reagiram positivamente ao teste foram considerados infectados e portadores do vírus, mesmo na ausência de sinais clínicos.

${ }^{1}$ BD Vacutainer ${ }^{\circledR}$ - Juiz de Fora, Brasil.

${ }^{2}$ Biovetech $\AA$, Indústria e Comércio de Produtos Biotecnológicos Ltda ME - Recife, Brasil. 
Para verificar as associações entre as variáveis qualitativas estudadas (raça, sexo e tipo de criação) e os resultados para Maedi-Visna, foi realizado o teste exato de Fisher. Para comparar as médias das variáveis quantitativas (frequência cardíaca, frequência respiratória e temperatura retal) entre animais soropositivos e soronegativos, foi realizado o teste $\mathrm{t}$ para duas amostras independentes, utilizando-se o programa SAS/1999, sendo consideradas significativas quando $\mathrm{P}<0,05$ (Zar, 1999).

Doze animais $(2,7 \%)$ em cinco propriedades distintas foram reagentes ao teste de IDGA. Não houve associação entre a soroprevalencia e a raça acometida (Tab. 1). A maior frequência na raça Santa Inês, provavelmente, deveu-se ao fato de essa raça ser a mais representativa na amostra, aproximadamente $50 \%$ dos animais avaliados. Não se observou associação entre soroprevalência e sexo (Tab. 1). Este aspecto já foi observado por Christodoulopoulos (2006) e Oliveira et al. (2006). Também não se verificou associação entre soropositivos e sistema de criação (Tab. 1). Quatro animais positivos pertenciam a propriedades de criação extensiva, e isto se explica pelo fato de essas propriedades estarem em formação, com os animais adquiridos de outras propriedades dentro e fora do Estado de São Paulo, o que pode ter facilitado a entrada do vírus nesses rebanhos. Não se observou diferença na frequência cardíaca, na respiratória e na temperatura retal entre os animais positivos $\mathrm{e}$ negativos.

Tabela 1. Resultado do teste de imunodifusão em gel de ágar para Maedi-Visna de ovinos da região de Araçatuba, SP

\begin{tabular}{|c|c|c|c|c|c|c|c|c|}
\hline \multirow{2}{*}{ Variável } & \multirow{2}{*}{ Grupo } & \multicolumn{2}{|c|}{ Negativo } & \multicolumn{2}{|c|}{ Positivo } & \multicolumn{2}{|c|}{ Total } & \multirow{2}{*}{$\mathrm{P}^{1}$} \\
\hline & & $\mathrm{n}$ & $\%$ & $\mathrm{n}$ & $\%$ & $\mathrm{n}$ & $\%$ & \\
\hline \multirow{7}{*}{ Raça } & Dorper & 6 & 1,4 & 0 & 0,0 & 6 & 1,4 & \multirow{7}{*}{0,7074} \\
\hline & Highlander & 6 & 1,4 & 0 & 0,0 & 6 & 1,4 & \\
\hline & Primera & 1 & 0,2 & 0 & 0,0 & 1 & 0,2 & \\
\hline & SRD & 150 & 33,8 & 4 & 0,9 & 154 & 34,7 & \\
\hline & Santa - Inês & 181 & 40,6 & 7 & 1,6 & 188 & 42,2 & \\
\hline & Suffolk & 86 & 19,4 & 1 & 0,2 & 87 & 19,6 & \\
\hline & Texel & 2 & 0,5 & 0 & 0,0 & 2 & 0,5 & \\
\hline \multirow{2}{*}{ Sexo } & Fêmea & 362 & 81,5 & 9 & 2,0 & 371 & 83,6 & \multirow{2}{*}{0,4262} \\
\hline & Macho & 70 & 15,8 & 3 & 0,7 & 73 & 16,4 & \\
\hline \multirow{3}{*}{$\begin{array}{l}\text { Tipo de } \\
\text { criação }\end{array}$} & Extensivo & 207 & 46,6 & 4 & 0,9 & 211 & 47,5 & \multirow{3}{*}{0,1051} \\
\hline & Intensivo & 161 & 36,3 & 8 & 1,8 & 169 & 38,1 & \\
\hline & Semi-intensivo & 64 & 14,4 & 0 & 0,0 & 64 & 14,4 & \\
\hline
\end{tabular}

Teste exato de Fisher.

SRD: sem raça definida.

A soroprevalência de Maedi-Visna observada, no presente trabalho, foi mais baixa que as relatadas no Rio Grande do Sul (Dal Pizzol et al., 1989; Ribeiro, 1993), no Rio Grande do Norte (Silva, 2003) e no Paraná (Sotomaior et al., 1997), que foram de $10,5 \%, 19,0 \%, 21,3 \%$ e $86,7 \%$, respectivamente, e próxima às observadas no Ceará (Araújo et al., 2004), Pernambuco (Oliveira et al., 2006) e Bahia (Martinez et al., 2007), respectivamente de $4,9 \%, 0,5 \%$ e $5,2 \%$.

A baixa prevalência, verificada neste trabalho, indica que o vírus pode ter sido recentemente introduzido na região. Um levantamento sorológico realizado no Estado de São Paulo, em 1996, com amostras coletadas de diversas regiões incluindo Araçatuba, resultou em prevalência zero (Dangelino et al., 1996). O mesmo resultado foi observado mais recentemente, na região de Botucatu-SP (Rosa, 2007). No presente trabalho, o fato de não se encontrarem animais doentes também pode indicar que essas infecções foram recentes ou que esses animais não desenvolveram a doença, o que ocorre apenas em 25-30\% dos animais soropositivos (Christodoupoulos, 2006). 
Pode-se concluir que a ocorrência de MaediVisna em ovinos na região de Araçatuba é baixa, não apresentando relação com a raça, sexo ou com o sistema de criação. O conhecimento desta prevalência fornece subsídios que auxiliam a elaboração e instalação de programas de controle da enfermidade.

Palavras-chave: ovino, Maedi-Visna, sorologia, IDGA

\section{ABSTRACT}

The seroprevalence of Maedi-Visna in sheep from Araçatuba region - SP, was determined and correlated to age, gender, breed, or sheep production systems. Blood samples were collected from 444 sheep, aging from two to 12 year-old. Both sexes and different breeds were sampled in 20 farms of this region. Physical examination was performed in all animals. Agar gel immunodiffusion test kit was used to diagnose in serum samples. Twelve animals, from five different farms, were AGID positive, yielding a seroprevalence of $2.7 \%$, with no correlation among breed, gender, or sheep production systems and the detection of the disease. No animal considered positive for Maedi-Visna showed clinical signs compatible with Maedi-Visna.

Keywords: sheep, Maedi-Visna, serology, AGID

\section{AGRADECIMENTOS}

À FAPESP pela concessão da bolsa de iniciação científica (processo n.06/51374-4), à autora H.P. Paulo.

\section{REFERÊNCIAS BIBLIOGRÁFICAS}

ARAÚJO, S.A.C.; DANTAS, T.V.M.; SILVA,J.B.A. et al. Identificação de MaediVisna vírus em pulmão de ovinos infectados naturalmente. Arq. Inst. Biol., v.71, p.431-436, 2004.

CALLADO, A.K.C.; CASTRO, R.S.; TEIXEIRA, M.F.S. Lentivírus de pequenos ruminantes (CAE e Maedi-Visna): revisão e perspectivas. Pesq. Vet. Bras., v.21, p.87-97, 2001.

CHRISTODOULOPOULOS, G. Maedi-Visna: Clinical review and short reference on

the disease status in Mediterranean countries. Small Rumin. Res., v.62, p.47-53, 2006.

DAL PIZZOL, M.; RAVAZZOLO, A.P.; GONÇALVES, I.P.D et al. Maedi-Visna: identificação de ovinos infectados no Rio Grande do Sul, Brasil, 1987-1989. Arq. Fac. Vet. UFRGS., v.17, p.65-76, 1989.

DANGELINO, J.L.; BORGES, A.S.; BOHLAND, E. et al. Sorologia para diagnóstico da infecção pelo vírus Maedi-Visna no Estado de São Paulo. In: CONGRESSO PANAMERICANO DE CIÊNCIAS VETERINÁRIAS,
15., 1996, Campo Grande. Anais.... Campo Grande: [s.n.], 1996. p.288. (Resumo).

INSTRUÇÃO NORMATIVA n ${ }^{\circ} 87$, de 10 de dezembro de 2004, aprova o Regulamento Técnico do Programa Nacional de Sanidade dos Caprinos e Ovinos [ do Ministério da Agricultura Pecuária e Abastecimento]. Diário Oficial da União: Brasília, em 20 de dezembro de 2004. Seção 1, p.13.

ISHIZUKA, M.M.; LEITE, L.O.; DINIZ, O. Epidemiologia e profilaxia de CAE e MaediVisna. Disponível em: $<$ http://www.cda.gov.br/www/programas/index.p hp?action $=$ view $\&$ cod $=22 \& n m=$ Sanidade $\% 20$ Ani mal>. Acessado: em 13 dez. 2005.

MARTINEZ, P.M.; COSTA, J.N.; SOUZA, T.S. et al., Prevalência sorológica da Maedi-Visna em ovinos no semiárido baiano. In: CONGRESSO BRASILEIRO DE BUIATRIA， 7., 2007, Curitiba. Anais...Curitiba; Associação Paranaense de Buiatria, 2007. CD-ROM.

OLIVEIRA, M.M.M.; CASTRO, R.S.; CARNEIRO K.L. et al. Anticorpos contra lentivírus de pequenos ruminantes em caprinos e ovinos em abatedouros do Estado de Pernambuco. Arq. Bras. Med. Vet. Zootec., v.58, p.947-949, 2006.

ROSA, E.P. Soroprevalência da pneumonia progressiva ovina (Maedi-Visna) na região de Botucatu-SP, 2007. 53f. Dissertação (Mestrado) Faculdade de Medicina Veterinária e Zootecnia, Universidade Estadual Paulista, Botucatu. 
RIBEIRO, L.A. Risco da introdução de doenças exóticas pela importação de ovinos. Bol. Lab. Reg. Diag., n.13, p.39-44, 1993.

SILVA, J.B.A. Levantamento sorológico pelo teste de imunodifusão em gel de agarose (IDGA) da lentivirose ovina em rebanhos do Rio Grande do Norte, Brasil, 2003. 58f. Dissertação (Mestrado) - Universidade Estadual do Ceará, Fortaleza.

SOTOMAIOR, C.; MILCZEWSKI, V. Relato de um rebanho ovino infectado pelo vírus MaediVisna no estado do Paraná. In: CONGRESSO BRASILEIRO DE MEDICINA VETERINÁRIA, 25., 1997, Gramado. Anais...Gramado [s.n] 1997. p.179. (Resumo).
TORSTEINSDOTTIR, S.; ANDRESDOTTIR, $\mathrm{V}$.; ARNARSON, $\mathrm{H}$. et al. Immune response to Maedi-Visna virus. Front. Biosci., v.12, p.15321543, 2007.

ZAR, J.H. Biostatistical analysis. 4.ed. New Jersey: Prentice Hall, 1999. 663p. 